\title{
DetecÇão da ResistênCIA de CAPIM-ARROZ (Echinochloa sp.) AO HeRbicida Quinclorac eM Regiões ORIZícolas do SUl do BRASIL ${ }^{1}$
}

\author{
Detection of Echinochloa sp. Resistance to Quinclorac in Rice Fields in Southern Brazil
}

\begin{abstract}
ANDRES, A. ${ }^{2}$, CONCENÇO, G. ${ }^{3}$, MELO, P.T.B.S. ${ }^{4}$, SCHMIDT, M. $^{5}$ e RESENDE, R.G. ${ }^{6}$
RESUMO - O monitoramento da ocorrência de plantas de capim-arroz resistentes ao herbicida quinclorac foi realizado no Rio Grande do Sul e em Santa Catarina, visando determinar a origem da resistência e sua disseminação, bem como detectar práticas de manejo ou condições edafoclimáticas provavelmente envolvidas na seleção e distribuição geográfica do biótipo resistente. As sementes foram coletadas, purificadas e homogeneizadas, sendo os estudos realizados em laboratório e casa de vegetação. Em laboratório, foi conduzido teste de germinação padrão, embebendo as sementes dos biótipos nas doses de 0x, 1x, 2x, 6x, 16x e 32x a concentração recomendada de quinclorac (375 $\left.\mathrm{g} \mathrm{ha}^{-1}\right)$, sendo avaliadas a curva de germinação e a porcentagem de controle aos 14 dias após semeadura (DAS); em casa de vegetação, foram utilizadas as mesmas doses, aspergidas sobre as plantas aos 20 dias após a emergência (DAE), com as plantas no estádio de quatro folhas a um perfilho. Foram avaliadas a porcentagem de controle e a massa seca aos $35 \mathrm{DAE}$; biótipos com coeficiente de resistência (RI) superior a quatro foram considerados resistentes. Neste estudo foram encontradas sementes de capimarroz resistentes ao herbicida quinclorac. Elaborou-se mapa de distribuição dos biótipos resistentes nas áreas amostradas dos Estados do Rio Grande do Sul e Santa Catarina. O herbicida profoxydim é alternativa de controle dos biótipos de capim-arroz resistentes a quinclorac.
\end{abstract}

Palavras-chave: coeficiente de resistência, arroz irrigado, controle.

\begin{abstract}
The monitoring of Echinochloa sp. plants resistant to quinclorac was conducted in Rio Grande do Sul and Santa Catarina, Brazil to determine the origin of resistance and its dissemination, as well as to detect practices or climatic conditions related to the selection and geographic distribution of the resistant biotype. The seeds were collected, purified and standardized, and trials conducted under growth chamber and greenhouse conditions. In the growth chamber, a standard germination test was conducted with the seeds being submitted to rates of $0 x, 1 x, 2 x, 6 x, 16 x$ and $32 x$ and to the recommended rate of quinclorac, followed by germination curve and seedlings survival evaluation 14 days after sowing (DAS); the same herbicide rates were evaluated under greenhouse conditions, applied over the plants 20 days after emergence (DAE). Dry weight and control were evaluated 35 DAE, and biotypes with RI above four were considered resistant. A map of both states was elaborated where distribution of resistance to quinclorac was showed graphically, followed by herbicide profoxydim test as an alternative for the resistant biotype control.
\end{abstract}

Keywords: resistance index, flooded rice, control.

Recebido para publicação em 24.7.2006 e na forma revisada em 27.2.2007.

2 Pesquisador de Herbologia, Embrapa Clima Temperado, BR 392, Km 78, 96010-900 Capão do Leão-RS, <andre@cpact.embrapa.br>; ${ }^{3}$ Eng.-Agr., M.Sc. em Fisiologia Vegetal - IB/UFPel, doutoran do em Fitotecnia, Dep. de Fitotecnia, Universidade Federal de Viçosa - DFT/UFV, 36570-000 Viçosa-MG, bolsista CNPq, <gconcenco@yahoo.com.br>; ${ }^{4}$ Eng.-Agr., D.Sc. em Ciência e Tecnologia de Sementes, PMP, Pelotas-RS, <ptmelo@brturbo.com.br>; ${ }^{5}$ Eng.-Agr.; ${ }^{6}$ Acadêmico do curso de Agronomia - UFPel/FAEM, Estagiário Embrapa Clima Temperado. 


\section{INTRODUÇÃO}

A cultura do arroz é amplamente difundida nos Estados do Sul do Brasil, ocupando área maior que 1 milhão de hectares (IRGA, 2006). Além de fonte de renda, é responsável pelo suprimento de grande parte dos carboidratos na dieta dos brasileiros. Dos fatores que limitam a produção de arroz, é preponderante a infestação das lavouras por plantas daninhas, cuja ausência de controle pode ocasionar perdas superiores a $85 \%$ na produção de grãos (Fleck et al., 2004).

Os herbicidas, dentro de um programa de manejo integrado, representam a principal ferramenta de controle das plantas daninhas. Dentre aqueles utilizados na lavoura de arroz está o quinclorac, mimetizador de auxina que reúne flexibilidade na aplicação (pré e pós-emergência), eficiência de controle em Echinochloa crusgalli e Aeschynomene rudis, baixa toxicidade ao homem e aos animais e seletividade à cultura do arroz. Esse principio ativo começou a ser usado nas regiões orizícolas dos Estados do Rio Grande do Sul e Santa Catarina no início da década de 1990, sendo utilizado intensamente até meados de 1999, quando começaram a surgir queixas sobre falhas de controle de capim-arroz e estudos realizados por instituições do Sul do País confirmaram a ocorrência de resistência (Eberhardt et al., 2000; Menezes \& Ramirez, 2000; Merotto Jr. et al., 2000).

Algumas espécies de Echinochloa ou biótipos no sul da Europa e Estados Unidos apresentam variações de sensibilidade ao herbicida quinclorac, e esse fato independe do histórico de aplicaçãos te (Heap, 2000). Grossmann (1998) constatou que raízes de capim-arroz intactas foram apenas três vezes mais sensiveis ao quinclorac que as de arroz, afirmando ainda que a parte aérea é a principal responsável pela seletividade.

Além disso, pode haver relação entre o quinclorac e a enzima acetilcoenzima-A carboxilase (ACCase). Quando colmos e raízes destacados das plantas de E. crusgalli foram tratados com quinclorac in vitro, a sintese de ACCase foi estimulada nos tecidos da raiz. Tratamentos com ACCase via sistema vascular levaram a incremento na atividade da ACC sintase em tecidos de colmos, mas não em plantas intactas, não ocorrendo mudanças na formação do etileno, na atividade da enzima 1-aminociclopropano-1-carboxilato sintase (ACC sintase) e nos níveis de ACC (Grossmann \& Scheltrup, 1997).

O mapeamento da ocorrência de resistência pode auxiliar na determinação da gravidade do problema e auxiliar na identificação de características climáticas ou de manejo em comum que estejam ocasionando a expressão da resistência ou apressando o processo de seleção do biótipo resistente. Além disso, o mapeamento pode mostrar se a resistência se desenvolveu isoladamente ou foi disseminada de algumas regiões para as demais. Processos de mapeamento da resistência de Euphorbia heterophylla aos herbicidas inibidores da enzima acetolactato sintase (ALS) foram conduzidos nos Estados do Rio Grande do Sul e Santa Catarina, e a metodologia foi adequada para determinação das possiveis causas ou origens da resistência (Vidal et al., 2004; Hernandes et al., 2005). Esses autores concluíram que a resistência se desenvolveu independentemente, sobretudo pela ausência de práticas de manejo ou rotação de principios ativos como forma de retardar o aparecimento de resistência.

O objetivo deste trabalho foi monitorar a ocorrência de plantas de capim-arroz resistentes ao herbicida quinclorac no Rio Grande do Sul e em Santa Catarina, para determinar a origem da resistência e sua disseminação aos demais locais, bem como detectar práticas de manejo provavelmente envolvidas na seleção e distribuição geográfica do biótipo resistente.

\section{MATERIAL E MÉTODOS}

As sementes foram coletadas durante dois anos nas regiões orizícolas dos Estados do Rio Grande do Sul e de Santa Catarina, em locais onde havia histórico de falhas na eficiência de quinclorac no controle de capim-arroz. A amostra de sementes era composta por cinco ou mais subamostras coletadas em pontos aleatórios ao longo da lavoura, retiradas de panículas maduras, uniformes e de aparência saudável (ausência de manchas e impurezas), representativas das demais plantas presentes na área. A amostra foi acondicionada em sacos de papel permeável, para facilitar a aeração 
das sementes, identificados com localidade, nome do produtor, área e anos de cultivo e utilização do mesmo herbicida, sistema de implantação e número de anos em que se observou o problema, acondicionados em caixas de poliestireno expandido, transportadas até a Estação Experimental Terras Baixas da Embrapa Clima Temperado, em Capão do Leão, RS, onde passaram por padronização (remoção de sementes muito diferentes das demais da mesma amostra) e receberam número de protocolo e tratamento de superação de dormência (Rosenthal et al., 2004), sendo em seguida submetidas aos ensaios de avaliação em laboratório (Carvalho et al., 2004) e casa de vegetação (Andres et al., 2002).

Em laboratório, foi avaliada a curva de germinação e controle 14 dias após semeadura (DAS), pelas Regras Oficiais para Análise de Sementes - RAS (Brasil, 1992) com modificações, para possibilitar os tratamentos herbicidas (Carvalho et al., 2004). A concentração-padrão foi calculada a partir da bula do herbicida, levando em consideração a dose aplicada em um hectare, com lâmina de água constante de $10 \mathrm{~cm}$; as concentrações adotadas nos experimentos constaram de $0,1,2,6,16 \mathrm{e}$ 32 vezes a registrada no MAPA.

Em casa de vegetação, o coeficiente de resistência (RI) foi estabelecido para o biótipo suscetivel de referência, cuja redução em 50\% no crescimento das plantas foi alcançada com dose de 0,45 vez a recomendada pela pesquisa, ou seja, qualquer biótipo avaliado posteriormente, controlado com dose similar, apresentaria $\mathrm{RI}=1$. Conseqüentemente, o uso de dose de 1,8 vez a recomendação $(\sim 2 x)$ resultou em $\mathrm{RI}=4$ e foi considerado motivo de distinção entre biótipos resistentes e suscetiveis. Esta dose normalmente é considerada adequada para detectar resistência em plantas daninhas (Kissmann, 1997).

Os experimentos foram instalados em delineamento experimental de blocos casualizados com quatro repetições, sendo os biótipos semeados em bandejas plásticas com solo isento de resíduos de herbicidas. As plantas se desenvolveram normalmente até 20 dias após a emergência (DAE), quando então foi realizado desbaste, sendo deixadas 50 plantas distribuídas em cinco linhas; posteriormente realizaram-se as aspersões de quinclorac $(+0,5 \% \mathrm{v} / \mathrm{v}$ de Assist), nas doses empregadas em laboratório, utilizando-se equipamento costal de pressão constante propelido a $\mathrm{CO}_{2}$ e barra munida de quatro bicos Teejet 110.015 , com volume de calda de $150 \mathrm{~L} \mathrm{ha}^{-1}$. As parcelas foram mantidas com lâmina de água constante a partir de dois dias após a aplicação do herbicida (DAA) até o momento das avaliações. Foram avaliadas a mortalidade de plantas (porcentagem de controle) e a massa seca de plantas na parcela 15 dias após aplicação (DAA), dado este usado para cálculo do coeficiente de resistência (RI). As plantas foram consideradas resistentes quando apresentavam RI igual ou superior a quatro, descrito pela fórmula:

$$
\mathrm{RI}=\frac{\mathrm{GR}_{50} \text { biótipo em avaliação }}{\mathrm{GR}_{50} \text { biótipo de referência }}
$$

em que $\mathrm{RI}=$ coeficiente de resistência e $\mathrm{GR}_{50}=$ dose necessária para reduzir em $50 \%$ o desenvolvimento do biótipo. O biótipo suscetivel de referência foi coletado em área da Embrapa Clima Temperado sem histórico de aplicação de herbicidas mimetizadores de auxina.

Após as avaliações de controle, as parcelas foram fotografadas e dez plantas coletadas para análise da massa seca. Procedeu-se à aspersão com profoxydim (inibidor da ACCase) na dose de $100 \mathrm{~g} \mathrm{ha}^{-1}$, visando avaliá-lo como alternativa de controle de capim-arroz nas áreas com confirmação de resistência ao quinclorac.

Foi realizada análise de variância pelo teste $\mathrm{F}$ a $5 \%$ de probabilidade, sendo executada análise de regressão em caso de significância estatística.

\section{RESULTADOS E DISCUSSÃO}

No teste em laboratório, observou-se que a germinação não foi influenciada pelo incremento na concentração de quinclorac, tanto para os biótipos resistentes quanto para os suscetiveis, sendo as diferenças atribuídas aos biótipos. Todas as sementes germinaram e iniciaram o processo de crescimento normalmente, no entanto plântulas originadas de sementes de biótipos suscetiveis apresentaram necrose três ou quatro dias após a emergência, e a morte ocorria até o décimo dia. Na curva de germinação, foram contabilizadas todas as sementes que efetivamente germinaram, 
independentemente de ocorrência de morte posterior (Figura 1). A diferença de germinação observada entre ecótipos foi atribuída ao vigor de desenvolvimento, pois os lotes de sementes foram submetidos a tratamento de superação de dormência antes do início dos experimentos. Concentrações mais elevadas de quinclorac ocasionaram sintomas de necrose intensa nos biótipos suscetiveis. Os biótipos resistentes, por sua vez, reduziram o crescimento, mas não apresentaram sintomas de necrose (dados não apresentados). Além disso, tanto na ausência como na presença do herbicida quinclorac, plântulas oriundas de sementes de biótipos resistentes se mostraram mais vigorosas, com crescimento mais rápido do que as oriundas de sementes de biótipos suscetiveis (Figura 1). Os niveis de controle observados em germinador se assemelharam aos de casa de vegetação.

O controle dos biótipos em casa de vegetação na dose (2x) de distinção entre resistente e suscetivel foi variável, porém foi possível identificar e agrupar os biótipos em três niveis: de baixa, moderada e alta resistência (Figura 2). O grupo de baixa resistência inclui genótipos provenientes de duas áreas: de onde somente plantas isoladas não são controladas e de onde a resistência ainda está ausente, em decorrência de intensidade de seleção baixa ou moderada (Saari et al., 1994). Os genótipos do grupo de alta resistência ocorreram em áreas cujas

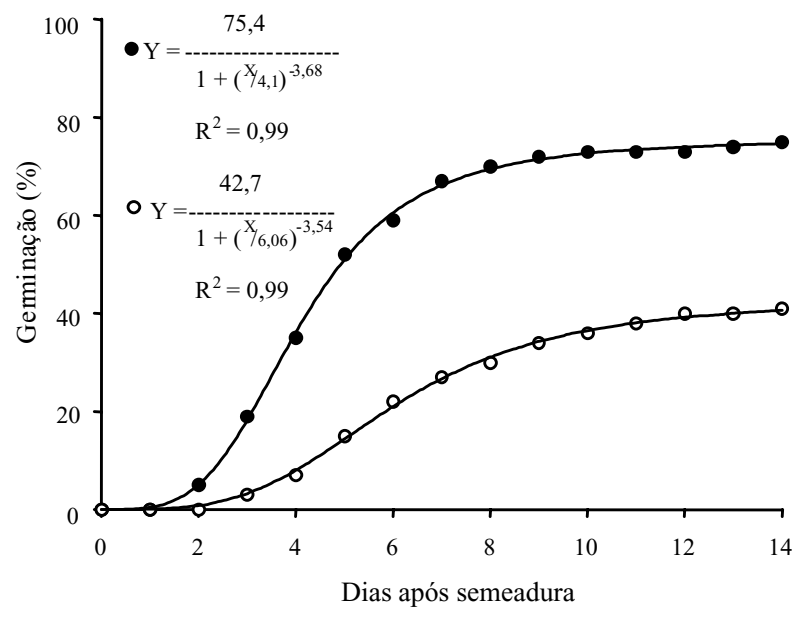

Figura 1 - Curva de germinação para biótipos de capim-arroz em função de dias após semeadura. Média de $10 \%$ dos genótipos mais resistentes $(\bullet)$ e mais suscetíveis (o). Embrapa Clima Temperado, Capão do Leão-RS, 2004. práticas culturais adotadas (ausência de métodos de controle alternativo, de rotação de culturas - uso intensivo do arroz irrigado - e de herbicidas de grupos químicos distintos) contribuíram para a rápida seleção das plantas resistentes e redução da freqüência das suscetiveis. Os genótipos com resistência moderada (no centro da Figura 2) foram provenientes de localidades onde a população passa por fase de transição, com redução da freqüência de plantas suscetiveis e incremento das resistentes (Vidal et al., 2004), em função da adoção de práticas de manejo diversificadas ou rotação de culturas ou de áreas, mas provavelmente mantendo o quinclorac como principal ferramenta de controle de capim-arroz nos anos de cultivo.

O maior vigor de germinação observado para o biótipo resistente, juntamente com o desenvolvimento mais vigoroso da planta, podem fazer com que o biótipo resistente passe a predominar nas áreas orizícolas mesmo quando o agente selecionador - no caso, o quinclorac - for removido, a não ser que outras características favoráveis das plantas tenham sido prejudicadas, em favor do maior vigor de arranque inicial. Conseqüentemente, práticas

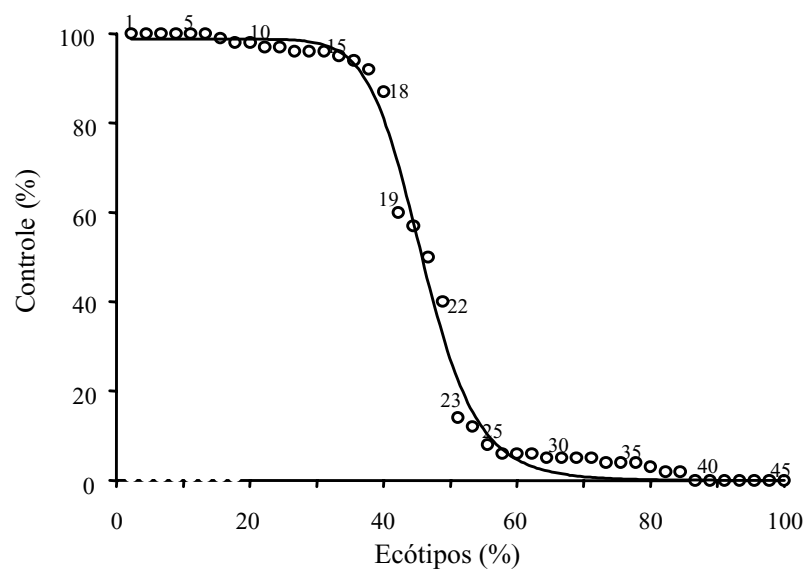

Áreas 1 a 18: Arroio Grande, Bagé, Camaquã, Capivari do Sul, Itaqui, Jaguarão, Mostardas, Rio Grande, Santa Vitória do Palmar, Uruguaiana (RS). Áreas 19 a 22: Camaquã, Dom Pedrito, São José do Norte, Viamão (RS). Áreas 23 a 45: Bagé, Itaqui, Mostardas, Pelotas, Santa Maria, São Gabriel (RS); Araranguá, Meleiro, Tubarão (SC).

Figura 2 - Controle dos biótipos de capim-arroz 35 DAE, com uso de $2 \mathrm{x}$ a dose recomendada de quinclorac pulverizado na parte aérea das plantas, em casa de vegetação. Cada ponto representa uma localidade amostrada, organizadas em ordem decrescente de controle. Embrapa Clima Temperado, Capão do Leão-RS, 2004. 
integradas, como rotação de culturas, ou adoção de práticas alternativas de controle de plantas daninhas seriam interessantes mesmo em associação com outro princípio ativo (Vargas et al., 2005) escolhido para o controle de capim-arroz nas áreas com problema.

Os valores de $\mathrm{GR}_{50}$ dos biótipos resistentes não se encontraram dentro do intervalo de doses avaliadas (até 32x). Em torno de 50\% dos biótipos avaliados apresentaram nivel de controle inferior a 10\%; um grupo intermediário (em torno de $10 \%$ dos biótipos avaliados), em fase de transição, mostrou controle ao redor de $50 \%$; e em torno de $40 \%$ apresentou controle acima dos niveis mínimos exigidos quando do uso de quinclorac (Figura 2). Além disso, o profoxydim foi eficiente e alcançou níveis de controle superiores a 93\% em todos os biótipos avaliados, permanecendo como alternativa de controle tanto dos biótipos resistentes como dos suscetiveis. Roman et al. (2004), trabalhando com azevém resistente ao glifosato, concluíram que a sensibilidade do biótipo resistente e suscetivel aos herbicidas inibidores da ACCase permaneceu inalterada e que estes seriam ferramenta no controle do biótipo resistente.

A distribuição de biótipos de capim-arroz resistentes ao herbicida quinclorac é observada principalmente no litoral do Rio Grande do Sul (Figura 3), onde as práticas de manejo mais marcantes incluem cultivo intensivo, baseado no controle químico de plantas daninhas, e ausência de rotação. O mais provável é que a resistência tenha se desenvolvido dentro do biótipo característico da região, uma vez que em algumas regiões foram encontradas amostras nas quais a resistência se encontra ainda em nivel intermediário, ou campos próximos com presença e ausência de resistência. Caso similar foi registrado em trabalho de mapeamento de E. heterophylla resistente aos inibidores de ALS (Vidal et al., 2004).

O surgimento de biótipos resistentes a herbicidas ocorre normalmente em áreas onde é prática freqüente o uso repetido e subseqüente do mesmo herbicida ou de diferentes herbicidas, porém com o mesmo mecanismo de ação - alta intensidade de seleção (Saari et al., 2004). Essa situação é bem comum no Rio Grande do Sul, como previamente citado. Por outro lado, no Estado de Santa Catarina,

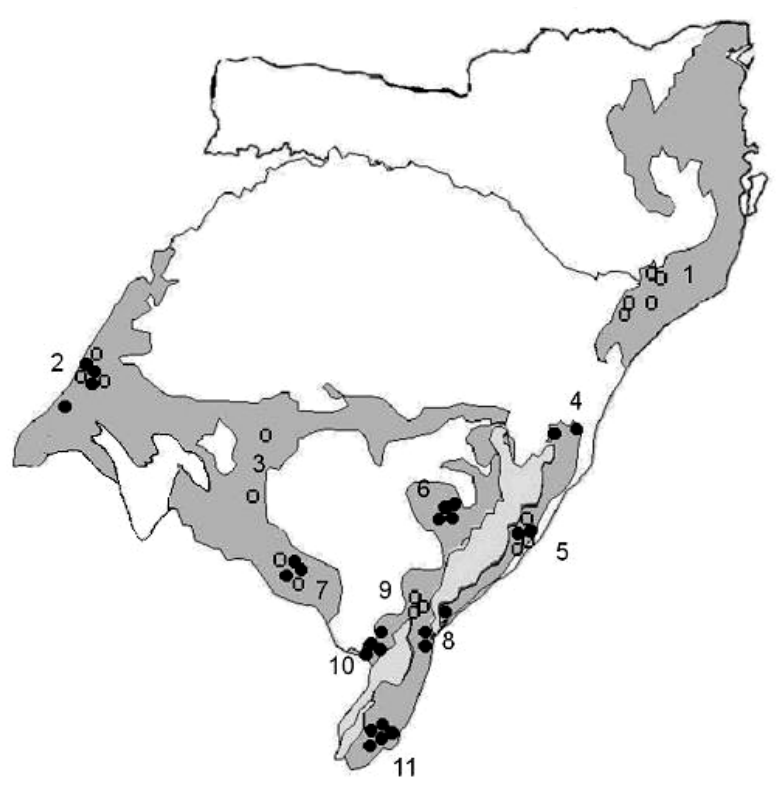

Regiões das seguintes cidades: (1) Araranguá/Meleiro/Tubarão; (2) Itaqui/Uruguaiana; (3) Santa Maria/São Gabriel; (4) Capivari do Sul/ Viamão; (5) Mostardas; (6) Camaquã; (7) Bagé/Dom Pedrito; (8) Rio Grande/São José do Norte; (9) Pelotas; (10) Arroio Grande/Jaguarão; (11) Santa Vitória do Palmar.

Figura 3 - Distribuição geográfica dos biótipos amostrados de capim-arroz resistentes $(\bullet)$ e suscetíveis $(\ddot{\mathrm{E}} \%)$ ao herbicida quinclorac, nas regiões orizícolas $(\square)$ dos Estados do Rio Grande do Sul e de Santa Catarina. Embrapa Clima Temperado, Capão do Leão-RS, 2004.

as áreas são menores e o manejo variado, associando herbicida e práticas culturais no manejo das plantas daninhas. Provavelmente em razão desse fato, não foram observados exemplares resistentes nas lavouras de Santa Catarina, entre as áreas amostradas. No entanto, Eberhardt \& Noldin (2001) relataram ocorrência de biótipos de capim-arroz resistentes ao quinclorac nos municípios de Tubarão e Araranguá.

Este estudo evidencia que a resistência de capim-arroz ao herbicida quinclorac está distribuída pelas áreas orizícolas da Zona Sul do Estado do Rio Grande do Sul e, ainda, ausente ou em início de disseminação nas áreas amostradas do Estado de Santa Catarina. Nas áreas onde a resistência já foi identificada e o problema tem incrementado rapidamente, sugere-se adotar estratégias imediatas de controle do biótipo resistente, entre elas rotação de herbicidas com diferentes mecanismos 
de ação, utilização de manejo integrado de plantas daninhas e rotação de culturas ou de áreas, se possivel, bem como práticas preventivas e monitoramento constante nas demais áreas. O biótipo resistente se mostrou mais competitivo nas características de desenvolvimento inicial, porém é conveniente verificar se não ocorre alteração em algum outro parâmetro do desenvolvimento, como forma de prever o equilíbrio populacional na ausência do agente selecionador.

\section{LITERATURA CITADA}

ANDRES, A. et al. Avaliação de ecótipos de capim-arroz resistentes a quinclorac. In: Congresso Brasileiro da Ciência das Plantas Daninhas, 23., 2002, Gramado. Resumos... Londrina: SBCPD/Embrapa Clima Temperado, 2002. p. 192.

BRASIL. Ministério da Agricultura e Abastecimento e de Reforma Agrária. Regras para análise de sementes. Brasília: SNAD/DNDV/CLAV, 1992. 365 p.

CARVALHO, S. J. P. et al. Identificação de biótipos de Bidens spp. resistentes aos inibidores da ALS através de teste germinativo. Planta Daninha, v. 22, p. 411-417, 2004.

EBERHARDT, D. S. et al. Resistência de capim-arroz (Echinochloa crusgalli) ao herbicida quinclorac. In: CONGRESSO BRASILEIRO DA CIÊNCIA DAS PLANTAS DANINHAS, 22., 2000, Foz do Iguaçu. Resumos... Londrina: SBCPD/Embrapa Clima Temperado, 2000. p. 512.

EBERHARDT, D. S.; NOLDIN, J. A. Capim-arroz resistente ao herbicida Facet em Santa Catarina. In: CONGRESSO BRASILEIRO DE ARROZ IRRIGADO, 2., 2001, Porto Alegre. Anais... Porto Alegre: IRGA, 2001. p. 513-515.

FLECK, N. G. et al. Manejo e controle de plantas daninhas em arroz irrigado. In: VARGAS, L.; ROMAN, E. S. (Eds.). Manual de manejo e controle de plantas daninhas. Bento Gonçalves: Embrapa Uva e Vinho, 2004. p. 251-321.

GROSSMANN, K.; SCHELTRUP, F. Selective induction of 1-aminocyclopropane-1-carboxylic acid (acc) synthase activity is involved in the selectivity of the auxin herbicide quinclorac between barnyard grass and rice. Pest. Biochem. and Physiol., v. 58, p. 145-153, 1997.

GROSSMANN, K. Quinclorac belongs to a new class of highly selective auxin herbicides. Weed Sci., v. 46, p. 707-716, 1998.

HEAP, I. M. International Survey of Herbicide Resistant Weeds. Disponível em: <www.weedscience.org $>$. Acesso em: 15 fev. 2004.
HERNANDES, G. C.; VIDAL, R. A.; WINKLER, L. M. Levantamento de práticas agronômicas e distribuição geográfica de Bidens spp. resistentes aos herbicidas inibidores de ALS nos estados do Rio Grande do Sul e do Paraná. Planta Daninha, v. 23, p. 677-682, 2005.

INSTITUTO RIOGRANDENSE DO ARROZ - IRGA. Anuário estatístico do arroz. Disponível em: <www.irga.rs.gov.br>. Acesso em: 10.5.2006.

KISSMANN, K. G. Plantas infestantes e nocivas. 2.ed. São Paulo: BASF Brasileira, 1997. 602 p.

MENEZES, V. G.; RAMIREZ, H. V. Resistance Echinochloa crus-galli L. to quinclorac in flooded in Southern Brazil. In: INTERNATIONAL WEED SCIENCE CONGRESS, 3., 2000, Foz do Iguaçú. Abstracts... Corvallis: IWSS, 2000. p. 140.

MEROTTO Jr., A. et al. Resistência de Echinochloa sp. à quinclorac. In: CONGRESSO BRASILEIRO DA CIÊNCIA DAS PLANTAS DANINHAS, 22., 2000, Foz do Iguaçu. Resumos... Londrina: Sociedade Brasileira da Ciência das Plantas Daninhas, 2000. p. 513.

ROMAN, E. S. et al. Resistência de azevém (Lolium multiflorum) ao herbicida glyphosate. Planta Daninha, v. 22, n. 2, p. 301-306, 2004.

ROSENTHAL, M. D. A. et al. Alternativas para superação de dormência em sementes de Echinochloa spp. através da associação de pré-secagem e métodos químicos. In: CONGRESSO BRASILEIRO DA CIÊNCIA DAS PLANTAS DANINHAS, 24., 2004, São Pedro. Anais... Londrina: Sociedade Brasileira da Ciência das Plantas Daninhas, 2004. CD-ROM.

SAARI, L. L.; COTTERMAN, J. C.; THILL, D. C. Resistance to acetolactate synthase inhibiting herbicides. In: POWLES, S.; HOLTUM, J. A. M. (Eds.). Herbicide resistance in plants: biology and biochemistry. Boca Raton: CRC Press, 1994. p. 83-139.

VALVERDE, B. E.; CASELEY, J. C.; RICHES, C. R. Prevention and management of herbicide resistant weeds in rice. Inglaterra, 2000. Disponível em: $<$ http:// www.weedscience.org>. Acesso em: 10 dez. 2002.

VARGAS, L. et al. Alteração das características biológicas dos biótipos de azevém (Lolium multiflorum) ocasionada pela resistência ao herbicida glyphosate. Planta Daninha, v. 23, n. 1, p. 153-160, 2005.

VIDAL, R. A. et al. A field survey of crop management practices and distribution of ALS resistant Euphorbia heterophylla in two states in Southern Brazil. Planta Daninha, v. 22, n. 3, p. 403-410, 2004. 